would impinge would be present, yet, the ventricular contrac ion veluy rapid, the conditions existing would favour the production of a sound and not that of a murmur. It must, however, be remembered that the first part of the ventricular contraction is unaccompanied by any sound at the aortic orifice, and that it is only at its latter portion that the semiIunar valves undergo the act of closure, and in this act present themselves suddenly against the ventricular stream that is entering the aorta. The strong ventricular stream thus impinges only for a moment against the membranous surface of the semilunar valves. In mitral regurgitation the ventricular stream impinges against the remains of the mitral membrane during the whole of the ventricular contraction; it is thus a relatively prolonged stream that i mpinges against a membrane, and hence the production of a murmur.

With regard to the mode of production of arterial murmurs, the same aconstic principles explain them. If the stethoscope is pressed against an artery part of the arterial membrane is pushed into the interior of the artery, and thus a membrane is opposed against a relatively prolonged stream. In aortic regurgitation the diastolic arterial bruit heard over the femoral artery is produced in the same manner.

In conclusion, to avoid confusion, I have omitted to state the combination of murmurs and sounds which may be produced at both orifices. If the sounds and murmurs of the heart are to be explained by the acoustic principle I have related, then it might be advisable to name them according to their mode of prodnction and locality in which they are produced. Thus, the first sound is the auricular sound, and the second the ventricalar. Marmurs produced at the mitral orifice and due to auricular contraction are mitral auricular systolic murmurs; these will be practically synchronous with the carotid pulse when they are functional in character-that is, when they simply replace the auricular sound owing to fatigue of the auricular muscle; they will precede the carotid pulse when they are organic-that is, when they are productd by marked delay of the auricular contraction owing to obstruction of the mitral orifice Marmurs prodaced at the mitral orifice, due to ventricular contraction, are mitral ventricalar systolic murmurs and are synchronous with the carotid pulse. Aortic ventricular systolic murmurs are produced at the aortic orifice owing to the ventricular systole; when these are due to stenosis of the orifice they will be synchronons with the carotid palse ; when functional - that is, due to simple fatigue of the ventricular muscle - they will succeed the carotid pulse; when due to undistensible conditions of the aorta they will be practically synchronous with the carotid pulse. Aortic systolic murmurs (regurgitant aortic) are due to the systole of the aorta and succeed the carotid pulse.

Buenos Ayres.

\section{MILK INFECTION.}

By Robert boxalt, M.D. Cainb., M.R.C.P., ASSISTAXT OBSTETHIC PHYSICIAN TO THF MIDDLLSI: $x$ HOSPITAL.

THE publication of "An Occurrence of Milk Infection" in THE LANCET ${ }^{2}$ has induced me to record a similar occurrerce which took place ten years previously in the General Lying-in Hospital. Between Jaly 5th and 13th five patients who had recently been delivered and six other nembers of the establishment were affected, the latter in some instances even more severely than the patients. Each case presented much the same symptoms: abdominal pain and tenderness more or less severe, ushered in by a slight rise of $t \in$ mperature with diarrhoea and tenesmus and followed by loss of appetite, extreme fetor of the breath, and a very coated, foul tongue. The stools were usually much relaxed, slimy, very irritating, and in one case developed the character of the green chopped spinach motions of an infant, and set up aphthous ulceration of the thighs wherever they came into contact. Later, moreover, towards the end of the first week of the illness, in some of the cases the mouth became sore. This soreness often began at the roof of the mouth, and aphthous ulcers subsequently made their appearance along the sides of the tongue on its under surface and along the inner side of the cheek, selecting those parts with which the teeth came into contact. The soreness was accomparied by considerable swelling. Some of the patients had lacerations about the valva more or less severe, and in each case the open suiface began to ulcerate rapidly and developed a similar aphthous character about the same time as the ulcers in the mouth began. The general condition, meantime, was not affected beyond the extent of the local mischief, and in all the lying-in women the course of the puerperium proceeded uninterruptedly towards recovery. In looking for the cause of the illness it was not difficult to satisfy oneself that the milk-supply was at fanlt. In the first place, inasmuch as this epidemic among patients and nurses occurred during a period of rather more than a week, it was apparent that some noxious flement must have been introduced into the kituation at that time only. In the second place, the illness occurring in patients in isolated wards (three in each, but only one affected), where, in view of the possibility of the introduction of infectious disease, every precaution was taken to prevent the spread of infection from one to another, and occurring in the cook and in five nurses, each kept strictly to her own ward (though in two cases attending to patients also sffected), this without doubt told against infection through the air. In the third place, the initial symptoms were those of an irritant poison taken into the alimentary canal. But the patients, at any rate, were on a strictly regulated diet, so that no ordinary indiscretion as regards food would account for the illness. On the other hand, it may be mentioned that the diet of the patients during and for the first three days after labour consisted largely of milk, and that all those affected had but recently been delivered. Moreover, the nurses affected and the cook were among those members of the resident staff who were in the habit of drinkirg milk at dinner and supper instead of beer. Furthermore, in the milk-supply itself at that time evidence pointing to the cause of the epidemic was afforded. For ten days or rather more the milk supplied to the hospital presented the following characters, for which I can vouch from personal observation, my attention having been drawn to it in the first instance by its peculiar taste, which I can only describe as rather earthy. The milk presented a deep yellow colonr, imparting to it a rich appearance, gave forth a faint, sickl odour, and though kept in a refrigerator very quickly turned sour. Several of the patients and nurses complained of its taste, and several of those affected, even before I hac occasion to suspect the milk, said that the milk did not agree with them. And, lastly, on July 12th a frekh millk-supply was obtained and the milk was boiled as soon as received at. the hospital; the epidemic then came to an erd.

In what way the milk bad bf come infected I am unable. to eay, and the milkman either could not or would not afford any clue. When questioned as to his customers, with a view to tracing other cases, he asserted that the hospital absorbed the whole of the milk sent by one farm, and none other; that he supplied no one else from the same source; and that he devoted that special snpply to the hospital use because it appeared rich and good. Bat as the corsumption in the hospital varied much from day to day, according to the number of patients, unless the dairyman's cows were exceptionally accommodating to meet the varying requirements of customers, it is obvious that there must have been a remainder which was unaccounted for. The dairyman stated that the farm had been inspected and that no disease was found among the stock. He owned to the practice of adding annatto to the milk, and gave me a sample which, as far as could be ascertained, in itself was free from suspicion. The conclusion which I myself came to at the time was that the disease must have criginated in some disease in the cow itself. The following table gives the dates of admission of the patients and of the appearance of the first symptoms and aphthous patches :-

\begin{tabular}{|c|c|c|c|c|}
\hline \multirow{2}{*}{ Case, } & \multirow{2}{*}{ Admitted. } & \multirow{2}{*}{$\begin{array}{c}\text { First } \\
\text { symptoms. }\end{array}$} & \multicolumn{2}{|c|}{ Aphthous patches. } \\
\hline & & & In mouth. & $\overbrace{\text { At vulva. }}$ \\
\hline 1 & $\begin{array}{l}\text { 1884. } \\
\text { July 3rd }\end{array}$ & $\begin{array}{l}1884 . \\
\text { July } 5 \text { th }\end{array}$ & $\begin{array}{l}1884 . \\
\text { July 1ith }\end{array}$ & $\begin{array}{l}1884 . \\
\text { July } 9 \text { th }\end{array}$ \\
\hline 2 & & &,$\quad 12$ th & , 13th \\
\hline 3 &,$\quad 5$ th & " 8 th & None & None \\
\hline 4 & " 6th &, 11th & July 13th & $\left\{\begin{array}{c}\text { July 11th; on } \\
\text { buttocks, July 14th }\end{array}\right.$ \\
\hline 5 & $"$ 11th & $" 13$ th & " 15 th & None \\
\hline
\end{tabular}

The cases above recorded appear to correspord in every respect with those alluded to by Dr. Niven in the paper to 
which reference has already been made, except that he makes no mention of the subsequent appearance of aphthous patches such as were often observed in the hospital cases. That these patches, both in the mouth and about the valva, partook of the nature of true aphthr I think there is little room to doubt. I regret that for want of time I omitted to subject the patches to microscopical examination. The peculiar green stools in Case 4 were remarkable, and, considering that as a rule a case of thrush only occurred on an average once in about 100 infants born in the hospital, it geems rather more than a coincidence that $t$ wo infants should have been affected with thrush during this epidemic, one in the same ward as Case 4, and the other in the same ward as Case 5. It is possible that the oidium albicans, in addition to the other poison, whatever its nature, may have been conveyed also by the contaminated milk. In any case, I consider that it is a subject for congratulation that the hand-fed children, of whom there were several in the hospital at the time, were all taking condensed instead of cow's milk. In November of the same year an isolated case of the same character as the others came under my observation. On admission to the hospital the patient was not well, having had diarrhoe $z$ and griping pains for two or three days. From her mother I subiequently ascertained that she had a son at home similarly aff $\exists c t \in d$, and that she herself, daughter, and son were in the habit of taking a glass or two of milk in the day, and that the milk had had a peculiar taste and smell, was of a "funny yellow colour," and rapidly turned wour, so much s) indeed that complaint had been made to the milkman The mother herself had not been affected. Dr. Niven draws attention to the fact that in the Manchester epidemic many appear to have escaped. It was the same with patien is and members of the resident hospital staff. Of the sixteen patients admitted between Jaly 2 nd and July 12th-i.e., between the admission of the first patient who fell ill and the date on which the milk-supply was changed-five only were affected, and not more than half of the resident staff of the hospital, though all probably partook of milk in a greater or less degree, each patient taking at least two pints in twenty-four hours for the first three days after delivery. As until the supply was changed it was not customary to scald the milk received into the hospital, the value of raising infected milk to boiling point with a view to warding off infection csuld not be determined. The question raised by Dr. Niven of the protective value of mere scalding is an amportant one. In conclusion, I may add that treatment was based on the assumption that the illness was due primarily to some irritant in the intestinal tract, and, with a view to eliminate the poison, a calomel purge was administered at the ou'set. If the diarrhcea continued the purge was followed by castor oil and opium, and later by quinine and opium in the form of pill.

Weymouth-street, W.

\section{SECONDARY HÆMORRHAGE IN A CASE OF NECKOSIS OF THE FEMUR; LIGATION}

\section{OF THE FEMORAL AND EXTERNAL ILIAC ARTERIES UNDER COCAINE; RECOVERY.}

BY R. N. HARTLEY, B.S. LOND., HONORARY SURGEON, LEEDS GENERAL INFIRMARY, ETC.

THE interesting report of a case of ligation of the femoral artery, by Mr. Suatham of Manchester, ${ }^{1}$ for secondary bæmorrhage suggested the desirability of putting on record the followirg case, the facts of which speak for themselves.

A boy ayed sixieen years was sent to me in March, 1889, on account of lorig-standing necrosis of the right femur. Briefly, the history was an attack of typhoid fever in 1886, followed by an acate periostitis of the whole shaft of the right femur, with some inflammation, apparently, of the hip and knee $j$ in's. The hip was stiff, but the head of the femur remained in its socket; the knee seemed partly subluxated and the heel rather drawn up $b_{y}$ the calf muscles. The thigh was much thickened, and several large sinuses discharged daily much pus. The irregular mass of new bone evidently enclosed a large loose sequestram. The boy was ill and worn from the long-existing suppuration, and on March 27th, 1889, the sinuses were dilated under ether for better examination, and through an opening made in the new mass of bone a large sequestrum was removed in two pieces, evidently the remains of the whole diaphysis of the femur. There was a very large irregular cavity, which was cleaned as thoroughly as possible and packed with strips of lint dusted over with iodoform. There was no serious bleeding during the operation. All went well till the following Sunday morning when I was hastily summoned to find the boy lying in a pool of blood, blanched, almost pulseless, and only partially conscious. It was practically impossible to make out the source of the bleeding, except that it came from the inside of the sloughy cavity and was probably arterial ; and as promptness of action was imperative fifteen drops of a 2 per cent. solution of cocaine hydrochlorate were injected under the skin over the upper part of the femoral artery, and with the help of a nurse the skin was incised, the artery exposed, and a double catgut ligature passed round it at a point about two inches below Poupart's ligament. The ligatures were separately tied upon the artery, and the vessel was divided between them. The bæmorrhage seemed to be quite controlled, and during the day the cavity of the thigh was emptied of clot and packing, cleansed, and repacked. All was quiet for a week, when again on the Sunday morning following I was called, to find that the boy had had a second similar severe bæmorrbage and stemed on the point of death. An injection of cocaine above Poupart's ligament allowed a slightly curved incision to be made a little above it, and a dissection was carried through the lower part of the abdominal wall, the peritoneum was pushed up, and a donble catgut ligature passed (as before) round the external iliac artery, the vessel being tied at two points and divided between them. The wound healed rapidly and without trouble, and after this there was no more bleeding at any time. Great care was taken, in the nursing \&c., to preserve the vitality of the limb, and the filling up of the thigh cavity was somewhat tedious, but the wearing of a 'l'homas's knee-splint enabled the patient to get about more comfortably, and the subsequent division of the tendo Achillis greatly lessened the shortening of the limb. The boy is now a healthy man aged twenty-two years, learning the mysteries of "business," but with a very vivid recollection of his experience of six years ago.

Looking back, it is easy to say that it would bave been better if the femoral artery had been ligatured higher up in the first instance, while the particular method of tying an artery in its continuity, the use of cocaine for the purpose, and other points might furnish suifable material for comment. The object, however, of this short commurication is simply to record the main facts of the case and to express the opinion that the trustfolness and courage of the boy greatly lightened a most anxious and critical experiec ce in a surgeon's life, and helped to aveyt a "surgical catastrophe."

Leeds.

\section{A CASE OF EMPYEMA WITH} COMPLICATIONS.

BY SURGEON-CAPTAIN S. G. ALLEN,

IATE ASSISTANT PATHOLOGIST AND CLINICAL OPHTHALMIC ASSISTANT, ST. MARY'S HOSPITAI.

With reference to an arlicle by Mr. Stephen Paget which appeared in THE LANCET of May 4th, recording the occurrence of cerebro-spinal symptoms of an obscure character during the treatment by irrigation of certain cases of empyema, I beg to forward the following extracts from the notes of a case of somewhat similar character which has recently come under my observation.

A man aged thirty.five years was taken ill eariy in January last with left-sided pleurisy, followed by cronpons pneumonia of the left lung, the right lung also becoming affected shortly afterwards. This double preumonia ran a favourable course for a time, the temperature returning to normal by the end of the second week of illness, and the pbysical signs showing that the consolidation of the lungs was clearing up. This process of resolution gradually came to a standstill, however, and the symptoms became of a more chronic character. His conoition varied from 